\title{
Identification of Genes Coding Aminoglycoside Modifying Enzymes in E. coli of UTI Patients in India
}

\author{
Abdul Rouf Mir, ${ }^{1}$ Yasir Bashir, ${ }^{2}$ Firdous Ahmad Dar, ${ }^{1}$ and M. Sekhar ${ }^{3}$ \\ ${ }^{1}$ Department of Biotechnology, Government Degree College Baramulla, Kashmir 193101, India \\ ${ }^{2}$ Department of Molecular Biology and Biotechnology, Tezpur University, Assam, India \\ ${ }^{3}$ Department of Biotechnology, The New College, Chennai, India \\ Correspondence should be addressed to Abdul Rouf Mir; roufonline@gmail.com
}

Received 24 January 2016; Revised 16 May 2016; Accepted 26 May 2016

Academic Editor: Wen-Jun Li

Copyright (C) 2016 Abdul Rouf Mir et al. This is an open access article distributed under the Creative Commons Attribution License, which permits unrestricted use, distribution, and reproduction in any medium, provided the original work is properly cited.

\begin{abstract}
This study is to probe the pattern of antibiotic resistance against aminoglycosides and its mechanism in E. coli obtained from patients from Chennai, India. Isolation and identification of pathogens were done on MacConkey agar. Antimicrobial sensitivity testing was done by disc diffusion test. The identification of genes encoding aminoglycoside modifying enzymes was done by Polymerase Chain Reaction (PCR). Out of 98 isolates, 71 (72.45\%) isolates were identified as E. coli and the remaining 27 (27.55\%) as other bacteria. Disc diffusion method results showed a resistance level of $72.15 \%$ for streptomycin, $73.4 \%$ for gentamicin, $63.26 \%$ for neomycin, $57.14 \%$ for tobramycin, $47.9 \%$ for netilmicin, and $8.16 \%$ for amikacin in E. coli. PCR screening showed the presence of four genes, namely, $r r s, a a c C 2, a a c A-a p h D$, and $a p h A 3$, in their plasmid DNA. The results point towards the novel mechanism of drug resistance in $E$. coli from UTI patients in India as they confirm the presence of genes encoding enzymes that cause resistance to aminoglycoside drugs. This could be an alarm for drug prescription to UTI patients.
\end{abstract}

\section{Introduction}

Infectious diseases continue to be a leading cause of mortality all over the world especially in developing countries with poorly accessed health services [1]. With the passage of time, the burden of bacterial infections is showing an ascending trend and this is largely due to the generation of resistance mechanisms by bacteria $[2,3]$. Among the various patterns of resistance, reports across the globe continue to emerge on the resistance to aminoglycoside antibiotics which otherwise have been reported as highly potent drugs against life threatening Gram-negative bacterial infections [4, 5]. Aminoglycosides act primarily by impairing bacterial protein synthesis through binding to prokaryotic ribosomes via $16 \mathrm{~S}$ ribosomal RNA (16S rRNA) and by disrupting the bacterial cell membrane integrity [6]. Aminoglycoside resistance has been reported in both Gram-negative and Gram-positive bacteria and main mechanisms that affect the efficacy of aminoglycoside drugs are a decreased uptake and/or accumulation of the drug in bacteria and the expression of aminoglycoside modifying enzymes (AMEs) that eventually inactivate the drugs [7]. Reduced drug uptake and active efflux of aminoglycosides have emerged as an additional mechanism of aminoglycoside resistance in Gram-negative bacteria [6]. Enzymatic inactivation of aminoglycoside drugs is caused by acetyltransferases, nucleotidyltransferases, and phosphotransferases through acetylation, adenylation, and phosphorylation, respectively. The genetic determinants of these enzymes are often located on mobile elements facilitating the rapid dissemination of the genes in various bacterial populations [8]. The emergence of complexity in defence mechanism has intensified the epidemiological research on these antibiotics and various reports have emerged to document the resistance patterns and the reasoning behind that. The comparative studies on the data on mechanisms of aminoglycoside resistance in bacteria isolated from various regions of the world have helped in understanding the spread of multidrug-resistant strains [9]. Similar studies have correlated the selective pressure of antibiotics and the patterns of combinations of aminoglycoside resistance mechanisms [10]. Resistance patterns and prevalence of the aminoglycoside 
TABle 1: Primer specification.

\begin{tabular}{|c|c|c|c|}
\hline Name & Subfamily & Primer sequence $(5 \rightarrow 3)$ & PCR product \\
\hline \multirow{2}{*}{$r r s$} & $r r s 1$ & GGATTAGATACCCTGGTAGTCC & \multirow{2}{*}{320} \\
\hline & $r r s 2$ & TCGTTGCGGGACTTAACCCAAC & \\
\hline \multirow{10}{*}{$\operatorname{aacC}$} & aacC1-1 & ACCTACTCCCAACATCAGCC & \multirow{2}{*}{169} \\
\hline & $\operatorname{aacC1-2}$ & ATATAGATCTCACTACGCGC & \\
\hline & aacC2-1 & ACTGTGATGGGATACGCGTC & \multirow{2}{*}{237} \\
\hline & aacC2-2 & CTCCGTCAGCGTTTCAGCTA & \\
\hline & aacC3-1 & CACAAGAACGTGGTCCGCTA & \multirow{2}{*}{185} \\
\hline & $\operatorname{aacC3}-2$ & AACAGGTAAGCATCCGCATC & \\
\hline & aacC4-1 & CTTCAGGATGGCAAGTTGGT & \multirow{2}{*}{286} \\
\hline & aacC4-2 & TCATCTCGTTCTCCGCTCAT & \\
\hline & aadC-1 & GCAAGGACCGACAACATTTC & \multirow{2}{*}{165} \\
\hline & aadC-2 & TGGCACAGATGGTCATAACC & \\
\hline \multirow{2}{*}{$a a c A-a p h D$} & aacA-aphD-1 & CCAAGAGCAATAAGGGCATA & \multirow{2}{*}{220} \\
\hline & $a a c A-a p h D-2$ & САСТАТСАТААССАСТАССС & \\
\hline \multirow{2}{*}{ aphA3 } & aphA3-1 & GCCGATGTGGATTGCGAAAA & \multirow{2}{*}{292} \\
\hline & aphA3-2 & GCTTGATCCCCAGTAAGTC & \\
\hline
\end{tabular}

modifying enzymes in clinical isolates showing multidrugresistant patterns have also been reported from various parts of India and it has been shown that high level aminoglycoside resistance genes are widely disseminated among Indian populations $[11,12]$. Though aminoglycoside drugs are being widely prescribed to patients in India, there is urgent need for assessment of emerging drug resistance pattern against these drugs. This study aims at studying antibiotic resistance pattern on commonly used aminoglycoside antibiotics in India using disc diffusion and molecular screening method (PCR) to detect the aminoglycoside resistance genes $r r s$ ( $r r s 1$ and $r r s 2$ ), a acC2 (aacC1-1, aacC1-2, aacC2-1, aacC2-2, aacC31, aacC3-2, aacC4-1, aacC4-2, aadC-1, and aadC-2), aacA$a p h D$ (aacA-aphD-1 and aacA-aphD-2), and $a p h A 3$ ( $a p h A 3-1$ and aphA3-2) in E. coli using eight sets of primers (Table 1). The same genes were earlier reported in bacteria of clinical isolates from Jordan University Hospital [13].

\section{Materials and Methods}

The study includes nonhospitalized patients attending clinical laboratory (Ehrlich Laboratory, Chennai, India). The clinical specimens were the urine samples collected from different patients from February to June 2015. The clean catch midstream urine samples were collected in sterile containers and transported within half an hour of collection to the laboratory. This study was duly approved by the Institutional Ethical Committee at University of Madras. Urine samples were collected from the patients after informed verbal consent. The mode of consent was duly approved by the ethical committee. A proper record of all the patients and healthy individuals has been maintained.

2.1. Isolation and Identification of Bacteria. Primary isolation was done on blood agar and MacConkey agar. Colonies from the primary isolation plates were picked up and Gram staining was done to study the morphology and Gram character. E. coli screening was carried out by carbohydrate fermentation test and the isolates were confirmed for genus and species by standard protocols [14]. Microscopic analysis was also used in identification.

2.2. Antibiotic Sensitivity Testing (Disc Diffusion Method). Antimicrobial sensitivity testing was done by Kirby-Bauer Antimicrobial Susceptibility Test (disc diffusion method) using Mueller-Hinton agar [15]. Six different antibiotics were tested and the zone size was measured. Amikacin, streptomycin, gentamicin, tobramycin, netilmicin, and neomycin (obtained from HiMedia, India) were taken and screening test for detection of high level aminoglycoside resistance (HLAR) in Enterococcus species was confirmed as per Clinical and Laboratory Standards Institute (CLSI) approved standards [16] The E. coli isolates were described as isolates with high level aminoglycoside resistance considering growth $\geq 2048 \mu \mathrm{g} / \mathrm{mL}$ for streptomycin, $\geq 512 \mu \mathrm{g} / \mathrm{mL}$ for gentamicin, $\geq 512 \mu \mathrm{g} / \mathrm{mL}$ for neomycin, $\geq 256 \mu \mathrm{g} / \mathrm{mL}$ for tobramycin, $\geq 256 \mu \mathrm{g} / \mathrm{mL}$ for netilmicin, and $\geq 256 \mu \mathrm{g} / \mathrm{mL}$ for amikacin. MICs were determined by Etest (AB Biodisk).

2.3. Isolation of Plasmid DNA. Procedure for the isolation of plasmid DNA from Gram-negative bacteria that showed resistance to at least two aminoglycoside antibiotics (38 samples) was followed as given in HiElute Miniprep DNA Isolation Kit from HiMedia, India. The isolated plasmids were stored at $-20^{\circ} \mathrm{C}$ in deep freezer till processed.

2.4. Identification of Genes Encoding Aminoglycoside Enzymes. Detection of aminoglycoside resistance genes $r r s$ ( $r r s 1$ and rrs2), aacC2 (aacC1-1, aacC1-2, aacC2-1, aacC2-2, aacC3-1, aacC3-2, aacC4-1, aacC4-2, aadC-1, and aadC-2), aacA-aphD (aacA-aphD-1 and aacA-aphD-2), and $a p h A 3$ (aphA3-1 and aphA3-2) from E. coli was done by PCR technique using Thermal Cycler (PTC 150, MJ Research). Blue mix DNA polymerase master mix, deoxynucleotide triphosphates (dNTPs), 
taq DNA polymerase, and the reaction buffer containing magnesium ions and the other required components were obtained from RBC Bioscience, India. Primers for the genes were purchased from Invitrogen (USA) through JOYVEL Biotech, India. Template DNA was isolated from E. coli. The working concentration of the primer was taken as $200 \mathrm{mM}$. The amount of PCR reaction mixture was taken as $50 \mu \mathrm{L}$ which included $25 \mu \mathrm{L}$ of blue mix DNA master mix, $5 \mu \mathrm{L}$ of forward primer, $5 \mu \mathrm{L}$ of reverse primer, $5 \mu \mathrm{L}$ of template DNA, and $10 \mu \mathrm{L}$ of TAE buffer. The PCR was performed with initial denaturation at $95^{\circ} \mathrm{C}$ for $3 \mathrm{~min}$ followed by 32 cycles each of denaturation at $94^{\circ} \mathrm{C}$ for $30 \mathrm{sec}$, annealing at $60^{\circ} \mathrm{C}$ for $45 \mathrm{sec}$, and extension at $72^{\circ} \mathrm{C}$ for two min for each gene.

The amplification products were analyzed by $0.8 \%$ agarose gel electrophoresis and the product size was compared with DNA markers. After treatment with ethidium bromide $(0.5 \mu \mathrm{g} / \mathrm{mL})$, the gels were visualized using gel-doc system (Bio-Rad Laboratories, USA).

\section{Results}

Out of the total 320 clinical specimens collected from a private clinical laboratory, Ehrlich Laboratory, only 98 $(30.6 \%)$ showed pathogenic growth. Out of 98 isolates, 71 (72.45\%) isolates were identified as E. coli and the remaining $27(27.55 \%)$ as other bacteria.

Phenotypic resistance to aminoglycoside antibiotics as analyzed by standard Kirby-Bauer disc diffusion method showed an overall mean resistance level of $73.4 \%$ for gentamicin, $72.15 \%$ for streptomycin, $63.26 \%$ for neomycin, $57.14 \%$ for tobramycin, $47.9 \%$ for netilmicin, and $8.16 \%$ for amikacin.

We further probed the mechanism of resistance at molecular level using PCR technique for those E. coli isolates that were resistant to at least two aminoglycoside antibiotics. These included 38 of the total E. coli samples. PCR was carried out using eight sets of primers from previously published data (Table 1) [13]. The screened isolates were shown to carry four genes, namely, rrs, aacC2, aacA-aphD, and aphA3. Primers for five subtypes of the same gene aacC were employed. The rrs was found to be the most abundant and was found in $26(68.4 \%)$ isolates and others included aacC gene in 18 (47.36\%), aphA3 gene in 13 (34.2\%), and aacC-aphD gene in $7(18.42 \%)$. No amplification of genes could be seen for seven isolates (Figures 1 and 2). We could find five isolates with three genes encoding aminoglycoside enzymes, sixteen isolates containing two genes, five isolates containing no genes, and other isolates containing a single gene. None of the isolates contained all the four genes in the plasmid genome. The 38 samples that were rendered to PCR analysis included patients aged 3-18 years ( 3 males and 5 females), $25-45$ years ( 4 males and 12 females), and 55-80 years (5 males and 9 females). The presence of three genes in $E$. coli isolates was found in single male (age: 45 years) and four females (age: 8 , 36,68 , and 72 years)

\section{Discussion}

Aminoglycoside resistance rates, phenotypes, and mechanisms of Gram-negative bacteria from infected patients

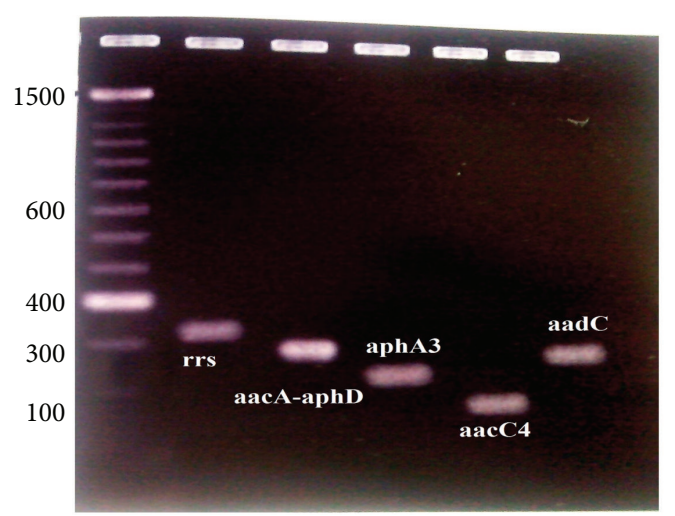

FIGURE 1: Gel documentation for genes encoding aminoglycoside modifying enzymes.

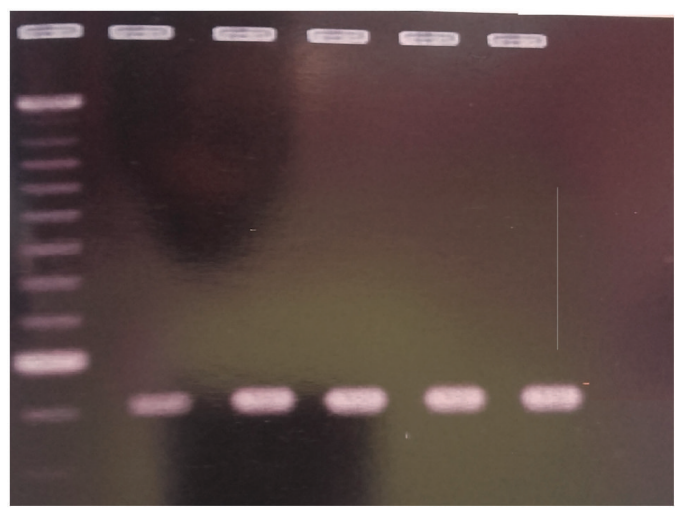

FIGURE 2: Gel documentation for rrs genes (five different samples) encoding aminoglycoside modifying enzymes.

across the world have shown progressive trends and it has been observed that resistance patterns have been disseminated in various bacterial species $[7,11]$. Since aminoglycoside drugs are thus far making a choice for clinicians for infectious treatments, it is highly significant to investigate the emerging resistance patterns in bacteria against these drugs, so as to understand the current resistance status and explore the more efficient means of dealing with these infectious agents. We screened resistance to aminoglycoside antibiotics using both phenotypic and genotypic methods. These results clearly indicate the enhanced resistance in the bacterial isolates against various aminoglycoside antibiotics. An earlier report that has employed Kirby-Bauer method to check the high level aminoglycoside resistance in Enterococci isolates has provided the similar inference for aminoglycoside resistance against gentamicin, streptomycin, and both of them together from Chennai, India [11]. Another report from infected patients in Upper Egypt has shown Gram-negative bacterial resistance against streptomycin, neomycin, kanamycin, gentamicin, and tobramycin. Similar to our observation, minimal resistance was reported against amikacin antibiotic [7]. Other various similar reports have published data showing growing multidrug resistance against most commonly used antibiotics in India [17-19]. Some latest reports emerging from different parts of India have 
shown an alarming rise of aminoglycoside drug resistance. One of such studies has shown high level resistance to gentamicin against five common aminoglycoside resistance genes $\operatorname{aac}\left(6^{\prime}\right)-I e-\operatorname{aph}\left(2^{\prime \prime}\right)-I a, \operatorname{aph}\left(2^{\prime \prime}\right)-I b$, aph $\left(2^{\prime \prime}\right)-I c, \operatorname{aph}\left(2^{\prime \prime}\right)$ $I d$, and $a p h\left(3^{\prime}\right)$-IIIa [20]. Another report shows high level aminoglycoside resistance for gentamicin, streptomycin, and both antibiotics with the detection of various aminoglycoside modifying enzyme encoding genes from southern part of India [11]. The reports from central India and north India have also shown a similar trend of rising aminoglycoside resistant isolates [21-24]. Studies from different parts of India show increasing resistance to aminoglycoside drugs among the bacterial isolates and more and more genes are being identified and found responsible for molecular mechanism of the drug resistance. This study now confirmed that one or more antibiotic resistance genes are carried on an $\mathrm{R}$ plasmid and more than one antibiotic could be a substrate for certain aminoglycoside modifying enzymes. The presence of different aminoglycoside resistance genes, namely, $r r s$, a acC2, $a a c A-a p h D$, and $a p h A 3$, in E. coli infers towards emergence of defence mechanism at molecular levels. Amikacin was observed to be the most potent drug among the used antibiotics. The results clearly infer towards the expression of aminoglycoside resistance genes in the $E$. coli isolates under study from India, which is a real problem and a challenge for urinary tract infection patients. The absence of genes in the five isolates can plausibly be explained by the presence of genes for which we did not include primers or the genes that are as yet unknown. Such a resistance would limit the choices of antibiotics available to clinicians to treat bacterial infections in patients. Earlier studies in India have shown the presence of $a a c(6)$, ant(2), and $a p h(3)$ genes in the $E$. coli, Klebsiella species, and Pseudomonas species bacterial isolates [23]. A latest study has shown an array of AMEs expressed by $\operatorname{aac}\left(6^{\prime}\right)$-Ie-aph $\left(2^{\prime \prime}\right)$-Ia and $a p h\left(3^{\prime}\right)$-IIIa genes responsible for causing high level of resistance in Enterococcus species against aminoglycosides [11]. It is clear that E. coli has assumed resistant patterns with the advancement of time and due to the exposure to the drugs. The resistance mechanisms lead to a compromising position for a clinician whether to subscribe the drugs to the patients or not. Various workers have developed combinational drugs with better bactericidal efficiencies and they may be a better choice for the treatment of infectious diseases caused by E. coli. This may be the only way to discourage the proliferation of antibiotic resistant microbes and to safeguard effectiveness of existing antimicrobial drugs. The concern of aminoglycoside resistance is serious and needs urgent attention. Regular surveillance of antimicrobial susceptibilities and effective management of bacterial infections needs urgent attention to limit the further spread of multidrug resistance in India.

\section{Competing Interests}

The authors declare that they have no competing interests.

\section{References}

[1] H. M. Zowawi, P. N. A. Harris, M. J. Roberts et al., "The emerging threat of multidrug-resistant Gram-negative bacteria in urology," Nature Reviews Urology, vol. 12, no. 10, pp. 570-584, 2015.

[2] A. L. Flores-Mireles, J. N. Walker, M. Caparon, and S. J. Hultgren, "Urinary tract infections: epidemiology, mechanisms of infection and treatment options," Nature Reviews Microbiology, vol. 13, no. 5, pp. 269-284, 2015.

[3] B. Mehrad, N. M. Clark, G. G. Zhanel, and J. P. Lynch, "Antimicrobial resistance in hospital-acquired gram-negative bacterial infections," Chest, vol. 147, no. 5, pp. 1413-1421, 2015.

[4] Z. Shokravi, L. Mehrad, and A. Ramazani, "Detecting the frequency of aminoglycoside modifying enzyme encoding genes among clinical isolates of methicillin-resistant Staphylococcus aureus," BioImpacts, vol. 5, no. 2, pp. 87-91, 2015.

[5] A. Kotwani, S. Kumar, P. K. Swain, J. C. Suri, and S. N. Gaur, "Antimicrobial drug prescribing patterns for communityacquired pneumonia in hospitalized patients: a retrospective pilot study from New Delhi, India," Indian Journal of Pharmacology, vol. 47, no. 4, pp. 375-382, 2015.

[6] M.-P. Mingeot-Leclercq, Y. Glupczynski, and P. M. Tulkens, "Aminoglycosides: activity and resistance," Antimicrobial Agents and Chemotherapy, vol. 43, no. 4, pp. 727-737, 1999.

[7] G. F. Gad, H. A. Mohamed, and H. M. Ashour, "Aminoglycoside resistance rates, phenotypes, and mechanisms of gram-negative bacteria from infected patients in upper Egypt," PLOS ONE, vol. 6, no. 2, Article ID e17224, 2011.

[8] M. S. Ramirez and M. E. Tolmasky, "Aminoglycoside modifying enzymes," Drug Resistance Updates, vol. 13, no. 6, pp. 151-171, 2010.

[9] K. Shi, S. J. Caldwell, D. H. Fong, and A. M. Berghuis, "Prospects for circumventing aminoglycoside kinase mediated antibiotic resistance," Frontiers in Cellular and Infection Microbiology, vol. 4, article 22, 2013.

[10] S. B. Vakulenko and S. Mobashery, "Versatility of aminoglycosides and prospects for their future," Clinical Microbiology Reviews, vol. 16, no. 3, pp. 430-450, 2003.

[11] E. Padmasini, R. Padmaraj, and S. S. Ramesh, "High level aminoglycoside resistance and distribution of aminoglycoside resistant genes among clinical isolates of Enterococcus species in Chennai, India," The Scientific World Journal, vol. 2014, Article ID 329157, 5 pages, 2014.

[12] K. Ajbani, C. Nikam, M. Kazi et al., "Evaluation of genotype MTBDRsl assay to detect drug resistance associated with fluoroquinolones, aminoglycosides and ethambutol on clinical sediments," PLoS ONE, vol. 7, no. 11, Article ID e49433, 2012.

[13] A. Shervington, L. Abbasi, and S. Bdour, "PCR amplification of four genes coding for aminoglycoside-modifying enzymes in bacteria of clinical isolates from Jordan University Hospital," World Journal of Microbiology and Biotechnology, vol. 17, no. 2, pp. 139-142, 2001.

[14] W. C. Winn, S. D. Allen, S. Allen et al., Koneman's Color Atlas and Textbook of Diagnostic Microbiology, Lippincott Williams \& Wilkins, Philadelphia, Pa, USA, 6th edition, 2006.

[15] J. H. Jorgensen and J. D. Turnidge, "Susceptibility test methods: dilution and disk diffusion method," in Susceptibility Test Methods: Dilution and Disk Diffusion Method, P. R. Murray, E. J. Baron, J. H. Jorgensen, M. A. Pfaller, and R. H. Yolken, Eds., pp. 1108-1127, ASM Press, Washington, DC, USA, 2003.

[16] Clinical Laboratory Standards Institute, "Performance standards for antimicrobial susceptibility testing; Twenty-fourth informational supplement," Tech. Rep. M100-S24, 2014. 
[17] S. Saha, S. Nayak, I. Bhattacharyya et al., "Understanding the patterns of antibiotic susceptibility of bacteria causing urinary tract infection in West Bengal, India," Frontiers in Microbiology, vol. 5, article 463, 2014.

[18] M. P. Bhatt, A. Patel, B. A. K. Sahni et al., "Emergence of multidrug resistant enterococci at a tertiary care centre," Medical Journal Armed Forces India, vol. 71, no. 2, pp. 139-144, 2015.

[19] A. Kumar, P. Kumar, and S. Basu, "Enterococcus fecalis sepsis and leukemoid reaction: an unusual association at birth," Journal of Pediatric Hematology/Oncology, vol. 37, no. 7, pp. e419-e420, 2015.

[20] K. Padmavathy, S. Praveen, R. Madhavan, N. Krithika, and A. Kiruthiga, "Clinico-microbiological investigation of catheter associated urinary tract infection by enterococcus faecalis: vanA genotype," Journal of Clinical and Diagnostic Research, vol. 9, no. 8, pp. DD05-DD06, 2015.

[21] V. S. Randhawa, L. Kapoor, V. Singh, and G. Mehta, "Aminoglycoside resistance in enterococci isolated from paediatric septicaemia in a tertiary care hospital in north India," Indian Journal of Medical Research, vol. 119, pp. 77-79, 2004.

[22] S. Mittal, P. Singla, A. Deep et al., "Vancomycin and high level aminoglycoside resistance in Enterococcus spp. in a tertiary health care centre: a therapeutic concern," Journal of Pathogens, vol. 2016, Article ID 8262561, 5 pages, 2016.

[23] M. Chaudhary and A. Payasi, "Resistance patterns and prevalence of the aminoglycoside modifying enzymes in clinical isolates of gram negative pathogens," Global Journal of Pharmacology, vol. 8, no. 1, pp. 73-79, 2014.

[24] V. A. Agarwal, Y. I. Jain, and A. A. Pathak, "Concomitant high level resistance to penicillin and aminoglycosides in Enterococci at Nagpur, Central India," Indian Journal of Medical Microbiology, vol. 17, pp. 85-87, 1999. 


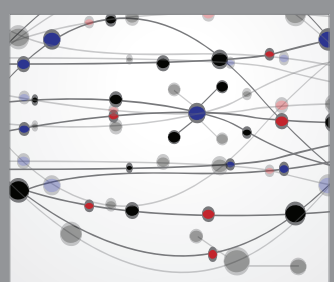

The Scientific World Journal
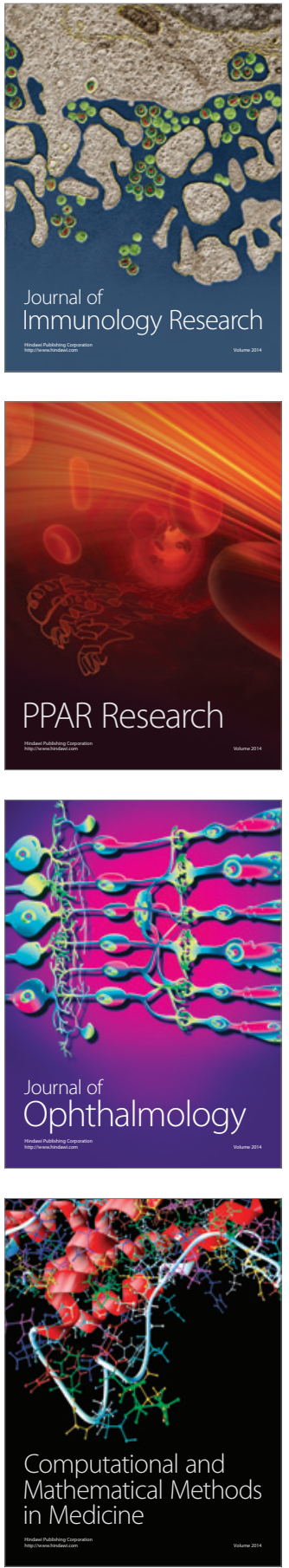

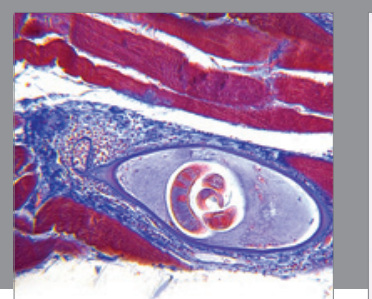

Gastroenterology Research and Practice

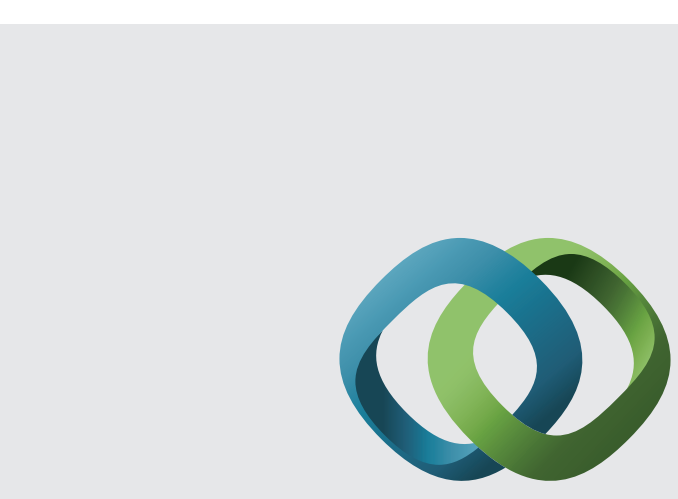

\section{Hindawi}

Submit your manuscripts at

http://www.hindawi.com
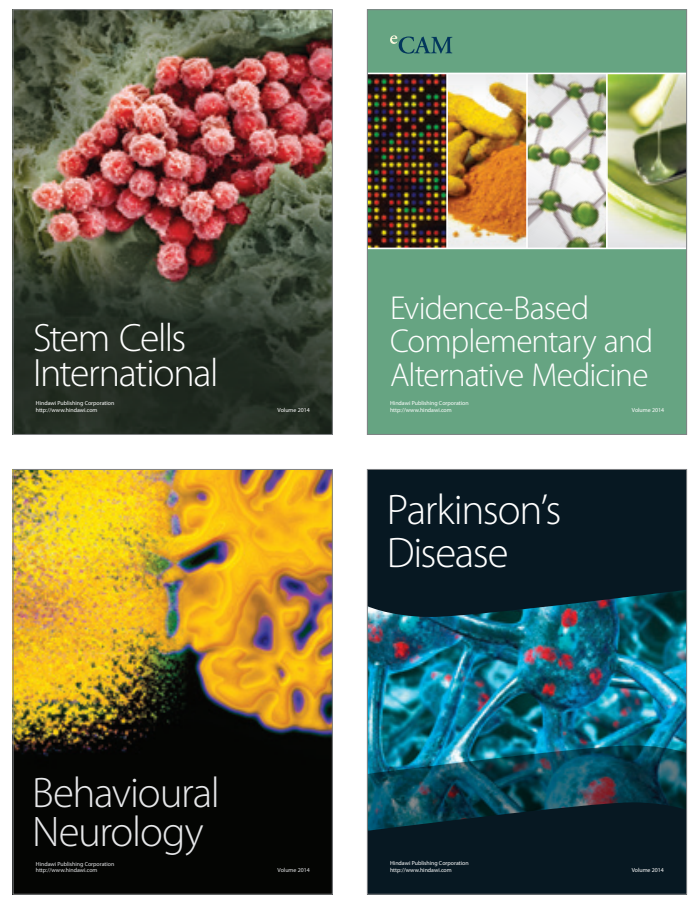
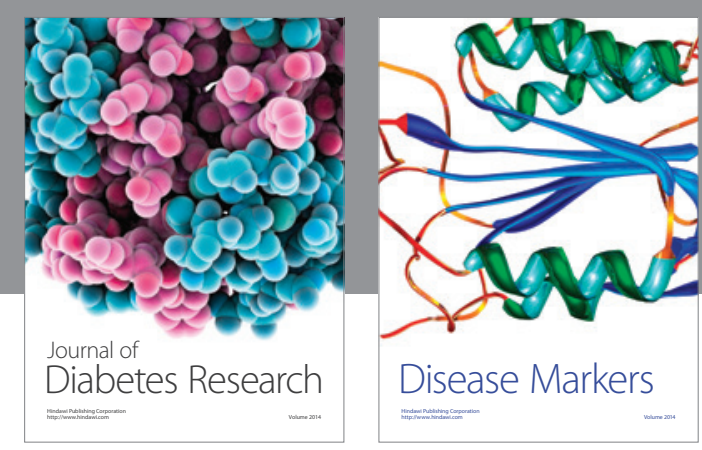

Disease Markers
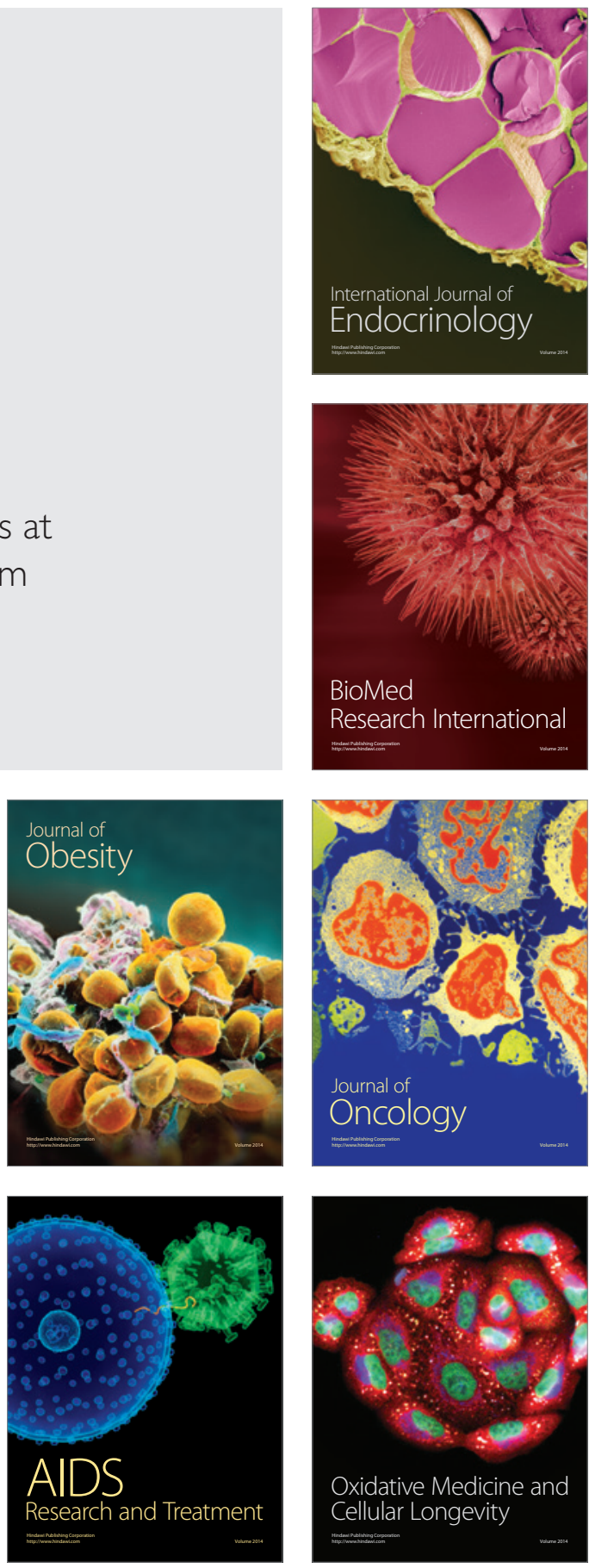